\title{
Tongue lesions in a Jordanian population. Prevalence, symptoms, subject's knowledge and treatment provided
}

\author{
Azmi-Mohammad-Ghaleb Darwazeh ${ }^{1}$, Amna-Abdulla Almelaih ${ }^{2}$
}

${ }^{1}$ BDS, MSc, PhD, FFDRCSI, Professor in Oral Medicine, Faculty of Dentistry; Jordan University of Science and Technology, Irbid ${ }^{2}$ BDS, MSc, Postgraduate student, Department of Oral Medicine \& Surgery, Faculty of Dentistry, Jordan University of Science and Technology, Irbid

Correspondence:

Faculty of Dentistry,

Jordan University of Science and Technology,

Irbid 22110, P O Box 3030,

Jordan

darwazeh@just.edu.jo

Received: $16 / 05 / 2010$

Accepted: 26/08/2010

\author{
Darwazeh AM, Almelaih AA. Tongue lesions in a Jordanian population. \\ Prevalence, symptoms, subject's knowledge and treatment provided. Med \\ Oral Patol Oral Cir Bucal. 2011 Sep 1;16 (6):e745-9. \\ http://www.medicinaoral.com/medoralfree01/v16i6/medoralv16i6p745.pdf

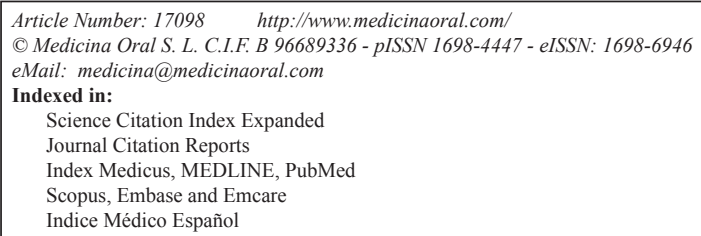

\begin{abstract}
Tongue lesions constitute a considerable proportion of oral mucosal lesions, and are health concern to both oral health care providers and public.

Objectives: The aim of this study was to determine the prevalence of tongue lesions and conditions among a group of Jordanian population attending dental clinics, in addition to assessment of their symptoms, knowledge, and treatment provided for their tongue lesions. Study design: A total of 2000 dental out-patients were screened for tongue lesions.

Results: Fissured tongue was the most common tongue lesion diagnosed in $11.5 \%$ of the subjects, followed by coated tongue $(8.2 \%)$, geographic tongue $(4.8 \%)$, hairy tongue $(2.4 \%)$ and median rhomboid glossitis $(0.5 \%)$. Symptoms were reported by $28 \%$ of the subjects with geographic tongue and $23 \%$ with fissured tongue. The majority of the subjects (ranging from $61.1 \%-86.4 \%$ ) were neither aware about their tongue lesions nor worried about their prognosis. Less than $50 \%$ of those who were aware of their tongue lesions sought medical advice.

Conclusion: The high prevalence of tongue lesions necessitates higher awareness of the general dental practitioner by their etiology, diagnosis and management.
\end{abstract}

Key words: Oral lesions, epidemiology, fissured tongue, geographic tongue, hairy tongue, coated tongue, median rhomboid glossitis. 


\section{Introduction}

Tongue lesions constitute a considerable proportion of oral mucosal lesions. The epidemiological studies have shown variable prevalence rates in different parts of the world (1-5). Repeatedly, the difference in the prevalence rates has been related to ethnic or racial factors, smoking habit and gender differences between populations studied, in addition to the general health status and the diagnostic criteria used $(1,2)$. However, apart of some cases of median rhomboid glossitis, the majority of these lesions is believed to be developmental anomalies (6), and oftenly discovered incidentally during routine oral examination. Nevertheless, the base-line data on tongue lesions are necessary for oral health planning and education. They are also of clinical and therapeutic importance for oral / dental health care providers.

Despite the abundance of the world-wide surveys on the prevalence of tongue lesions, reviewing the literature revealed the lack of studies that explored weather the affected subjects were aware of the existence of their tongue lesions. In addition, the proportion of subjects experience symptoms and the subject's knowledge about these commonly encountered tongue lesions has not been investigated, nor the treatment attempted for the management of these lesions by the general dental practitioners. The aims of this study were to determine the prevalence of the common tongue lesions in a group of healthy adult Jordanian population, and to assess the subjects symptoms, awareness of their tongue lesions and the type of the treatment provided for their management.

\section{Subjects and Methods}

A total of 2000 consecutive apparently healthy dental out-patients attending the Initial Treatment Unit at the Dental Teaching Center; Faculty of Dentistry in Jordan University of Science and Technology were included in the study. All subjects were attending for routine dental check up or for dental treatment, but none of the subjects was attending for diagnosis or treatment of an oral soft tissue lesion. The subjects were interviewed regarding their medical history and tobacco smoking habit. Subjects who complained from oral dryness, used antibiotics or antifungal agents over the past three months or who have any systemic disease, or taking any medication known to affect the oral mucosa were not included in the study. Any subject who reported having diabetes mellitus, anaemia, allergy or dermatological disease such as psoriasis was also not included in the study.

All the subjects (or their guardians) signed a formal consent form approved by the Institutional Review Board at the University. The clinical examination for the presence of tongue lesions was conducted by one of the authors (AAA) according to the method proposed by WHO (1980) (7), while the subject was seated on a dental chair using a conventional dental mirror and a probe and under artificial light.

Tongue lesions (fissured tongue, geographic tongue, coated tongue, hairy tongue and median rhomboid glossitis) were diagnosed according to the criteria determined by WHO (1980) (7). After clinical examination, the subjects with tongue lesions were asked whether they were aware about the existence of the lesions, or whether feeling any symptoms related to the lesions. The open-end type of questions was used for this purpose. Only subjects who were aware about the existence of their lesions were interviewed regarding their knowledge about the cause of their condition and whether they sought consultations from a dentist, and whether received any treatment.

Statistical analysis was performed using Statistical Package for Social Sciences (SPSS) software version 11 (SSPS ${ }^{\circledR}$ Inc., Chicago, IL, USA). Chi-square test was used to compare the differences in age, gender, and smoking habits as well as differences in the prevalence of lesions. P vale $<0.05$ was considered statistically significant.

\section{Results}

A total of 2000 dental out-patients divided into 762 (38.1\%) males and 1238 (61.9\%) females were included in the study. The subject's age ranged from 13 to 88 years with mean age was 34.1 (SD 14) years. A total of $342(17.1 \%)$ subjects were cigarette smokers. (Table 1) describes the prevalence of tongue lesions diagnosed among the study subjects and the proportion of those who reported symptoms. Tongue lesions were diagnosed in $29.9 \%$ of the study subjects. Fissured tongue was the most common lesion and diagnosed in $11.5 \%$ of the subjects, while median rhomboid glossitis was the least common lesion. In general, the prevalence of tongue lesions was significantly higher among males compared to females ( $\mathrm{P}=0.0003)$, except for combined geographic and fissured tongue and median rhomboid glossitis. None of the subjects with hairy tongue, coated tongue or median rhomboid glossitis reported symptoms.

The subjects were divided into age groups with 10-year intervals. Statistical analysis showed that the prevalence of geographic tongue was significantly decreasing with age $(\mathrm{P}=0.015)$, while the prevalence of fissured tongue was significantly increasing with age $(\mathrm{P}<0.0001)$ (Fig. 1). In addition, the prevalence of hairy tongue was significantly higher among cigarette smokers compared to non smokers $(\mathrm{P}<0.0001$; (Table 2).

(Table 3) shows the prevalence of subject's awareness about the presence of their tongue lesions, their knowledge about the cause of the lesions, whether they sought any medical consultation and the treatment given. The subject's interview revealed a relatively low awareness 
Table 1. The prevalence of common tongue lesions and conditions and associated symptoms among the study subjects.

\begin{tabular}{|l|c|c|c|c|c|}
\hline \multicolumn{1}{|c|}{ Tongue lesions } & $\begin{array}{c}\text { Male (n=762) } \\
\text { N (\%) }\end{array}$ & $\begin{array}{c}\text { Female (n=1238) } \\
\mathbf{N}(\mathbf{\%})\end{array}$ & P-value & $\begin{array}{c}\text { Total } \\
\mathbf{N}(\mathbf{\%})\end{array}$ & $\begin{array}{c}\text { Symptoms } \\
\text { N (\%) }\end{array}$ \\
\hline Fissured tongue & $98(12.9)$ & $132(10.7)$ & 0.003 & $230(11.5)$ & $53(23)$ \\
\hline Coated tongue & $84(11.0)$ & $79(6.4)$ & $<0.0001$ & $163(8.1)$ & $0(0.0)$ \\
\hline Geographic tongue & $28(3.7)$ & $68(5.5)$ & 0.039 & $96(4.8)$ & $27(28.1)$ \\
\hline Hairy tongue & $44(5.8)$ & $15(1.2)$ & $<0.0001$ & $59(2.9)$ & $0(0.0)$ \\
\hline Geographic and fissured tongue & $12(1.6)$ & $28(2.3)$ & 0.18 & $40(2.0)$ & $10(25)$ \\
\hline Median rhomboid glossitis & $5(0.6)$ & $5(0.4)$ & 0.3 & $10(0.5)$ & $0(0.0)$ \\
\hline \multicolumn{1}{|c|}{ Total } & $271(35.6)$ & $327(26.4)$ & 0.0003 & $598(29.9)$ & $90(4.5)$ \\
\hline
\end{tabular}

Table 2. The relationship of tongue lesions to tobacco smoking habit.

\begin{tabular}{|l|c|c|c|}
\hline \multicolumn{1}{|c|}{ Tongue lesions } & $\begin{array}{c}\text { Non-smokers } \\
\mathbf{N = 1 6 5 2}\end{array}$ & $\begin{array}{c}\text { Smokers } \\
\mathbf{N = 3 4 2}\end{array}$ & P-value \\
\hline Fissured tongue & $187(11.3 \%)$ & $43(12.6 \%)$ & 0.5 \\
\hline Geographic tongue & $85(5.1 \%)$ & $11(3.2 \%)$ & 0.3 \\
\hline Hairy tongue & $13(0.8 \%)$ & $46(13.4 \%)$ & $<0.0001$ \\
\hline Median rhomboid glossitis & $6(0.4 \%)$ & $4(1.2 \%)$ & 0.1 \\
\hline
\end{tabular}

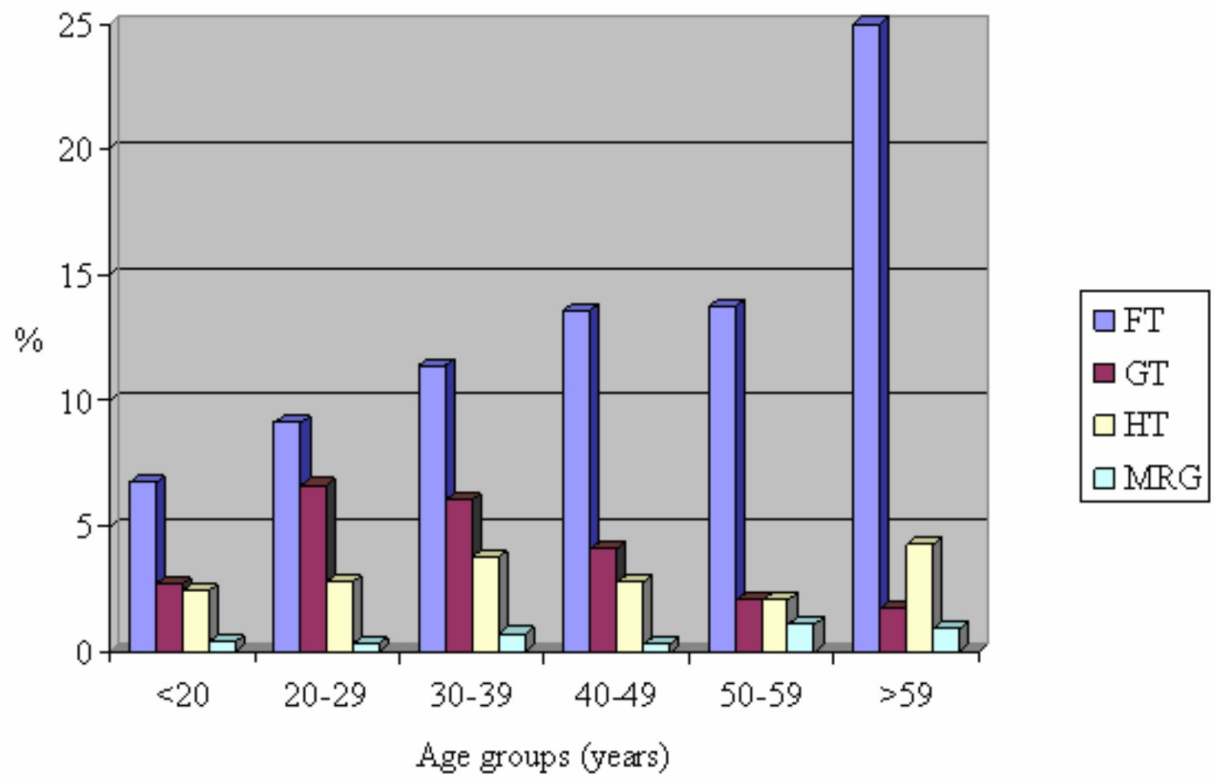

FT: fissured tongue, GT: geographic tongue, HT: hairy tongue, MRG: median rhomboid glossitis

Fig. 1. Prevalence of tongue lesions in different age groups. 
Table 3. The subject's awareness and knowledge of their tongue lesions, and the treatment given.

\begin{tabular}{|c|c|c|c|c|}
\hline Tongue lesions & $\begin{array}{c}\text { Subject's } \\
\text { awareness }\end{array}$ & Subject's knowledge & $\begin{array}{c}\text { Sought } \\
\text { treatment }\end{array}$ & Treatment given \\
\hline $\begin{array}{l}\text { Fissured tongue } \\
\qquad \mathrm{N}=230\end{array}$ & $73(31.7 \%)$ & $\begin{array}{l}\text { No idea } 57(78.1 \%) \\
\text { Normal variation } 10(13.7 \%) \\
\text { Inherited } 2(2.7 \%) \\
\text { Smoking } 2(2.7 \%) \\
\text { Diabetes mellitus } 1(1.4 \%) \\
\end{array}$ & $13(17.8 \%)$ & $\begin{array}{c}\text { No treatment } 8(61.5 \%) \\
\text { Mouth wash } 3(37.5 \%) \\
\text { Antifungals } 2(15 \%)\end{array}$ \\
\hline $\begin{array}{c}\text { Geographic } \\
\text { tongue } \\
\mathrm{N}=96\end{array}$ & $37(38.5 \%)$ & $\begin{array}{l}\text { No idea } 23(62.2 \%) \\
\text { Normal variation } 9(24.3 \%) \\
\text { Fungal infection } 3(8.1 \%) \\
\text { Friction } 1(2.7 \%) \\
\text { Smoking } 1(2.7 \%) \\
\end{array}$ & $4(10.8 \%)$ & $\begin{array}{c}\text { No treatment } 2(50 \%) \\
\text { Antifungals } 2(50 \%)\end{array}$ \\
\hline $\begin{array}{l}\text { Hairy tongue } \\
\qquad \mathrm{N}=59\end{array}$ & $8(13.5 \%)$ & $\begin{array}{l}\text { No idea } 3(37.5 \%) \\
\text { Smoking } 3(37.5 \%) \\
\text { Fungal infection } 1(12.5 \%) \\
\text { Friction } 1(12.5 \%)\end{array}$ & $2(25 \%)$ & $\begin{array}{l}\text { Antifungals } 1(50 \%) \\
\text { Folk medicine } 1(50 \%)\end{array}$ \\
\hline
\end{tabular}

bout the existence of tongue lesions ranging between $13.5 \%-38.5 \%$ as shown in (Table 3 ). None of the subjects with median rhomboid glossitis was aware of their tongue lesion. Similarly the minority of those who were aware of their tongue lesions sought medical consultation ranging between $10.8 \%$ and $25 \%$. As shown in (Table 3), the majority of the subjects who sought treatment were prescribed unnecessary medications for their tongue lesions.

\section{Discussion}

Tongue lesions have been reported as being more prevalent in haematological disorders, diabetes mellitus, dermatological diseases and some gastrointestinal diseases (8). Therefore, to avoid the influence of systemic disease on the prevalence of tongue lesions, this study was conducted on apparently healthy subjects.

Fissured tongue was the most common tongue lesion in this group of Jordanians with a prevalence of $11.5 \%$. This confirms the finding of a previous study among Jordanians were it was detected in $11.4 \%$ of the subjects (2). However, much higher prevalence $(27.3 \%)$ was reported in Brazil (9) and lower prevalence (1.4\%) was reported among Saudi dental patients (10). These variations in prevalence may be related to ethnicity, the criteria used to diagnose fissured tongue or the age of the studied subjects. Interestingly, our finding of increasing prevalence of fissured tongue with advancing age among our population has been reported in other ethnic groups (11). Advanced age has been reported to be associated with hyposalivation, which is counted as a contributory factor to the development of fissured tongue (12). It is tempting to speculate that other unidentified factor(s) may be contributing to the increased preva- lence of fissured tongue to advancement of age, since none of our subject was complaining of mouth dryness. In our study, $23 \%$ of the subjects with fissured tongue reported symptoms. The majority of them (66\%) had soreness with acidic food and drinks. Usually, fissured tongue is asymptomatic but it can be anticipated that symptoms may present if the fissures were deep enough to retain food debris in their base, which become reservoir for bacteria and subsequently inflamed.

The prevalence of coated tongue $(8.2 \%)$ in this study is in accordance with that reported in a previous Jordanian study (9.2\%) (2). This condition was considered the most common tongue lesion among a Turkish population, with a prevalence of $2.1 \%$ (3). However, our results confirm the other findings of a significant association between smoking and both coated tongue $(3,13)$ and hairy tongue $(2,14,15)$. The lack of a significant association between median rhomboid glissitis and smoking may be explained by the relatively small number of the diagnosed lesions in this study.

The $4.8 \%$ prevalence of geographic tongue in this study is lower than $6.8 \%$ previously reported among Jordanians (2). This may be explained by the transient nature of geographic tongue which nictitates longitudinal, rather than cross-sectional, studies to determine its actual prevalence. Our finding of higher prevalence of geographic tongue among young age subjects is consistent with that reported in other parts of the world $(1,3,14,15)$. In general, the reported association of geographic tongue to gender is inconsistent. While our results demonstrate higher prevalence among females, which was also the finding in Thailand (16), others reported higher prevalence among male children in Hungary (17). On the other hand, other studies found no gender differenc- 
es in the prevalence of geographic tongue $(1,15)$. The transient nature of this condition and the ethnic variations may partly explain this discrepancy in results.

Approximately $28 \%$ of those with geographic tongue reported symptoms, where the majority of them (63\%) had soreness with acidic food and drink. Apparently this may be due to the higher sensitivity of the depapillated areas on the tongue dorsum to the acidic food. Few studies have shown that geographic tongue was more common in atopic patients (15) and patients with psoriasis (18). However, a large scale study reported a strong association of geographic tongue to race / ethnicity but did not find a significant association of geographic tongue to age, gender, diabetes mellitus or dermatological diseases (19).

Reviewing the dental literature reveals wide variation in the prevalence of hairy tongue ranging from $0 \%$ (17) to $11.3 \%$ (3). This reflects differences in diagnostic criteria used to diagnose the case, in addition to ethnic and smoking habit variations. The observed and reported higher prevalence among males was attributed to the increasing smoking habit among males (2).

Median rhomboid glossitis is believed to be either a form of Candida infection or a developmental anomaly (6). Nevertheless, it was not within the objectives of this survey to study the etiology or pathogenesis of this condition. Since none of the subjects with median rhomboid glossitis reported symptoms or were aware of its existence, they did not seek treatment. However, the dental practitioner should be able to recognize this condition and identify its etiology to provide the appropriate treatment if needed. Due to the limited number of subjects included in this study, the results of this survey can not be generalized to the Jordanian populations. Larger scale national-wide studies are needed to determine the prevalence of tongue lesions in Jordanians.

Despite the abundance of the epidemiological surveys on the prevalence of tongue lesions, none of them, up to author's knowledge, attempted to explore the subjects awareness of the existence of their tongue conditions, the presence of symptoms, the proportion of those who sought dentist consultation, or the type the treatment provided. The lower level of awareness of the subjects with their tongue condition may explain the fact that only few of them requested medical / dental consultation regarding these conditions. In additions, inappropriate therapy was attempted by some dentists, where antifungal agents were prescribed for cases of geographic tongue, hairy tongue or fissured tongue, though these conditions are not considered fungal infections. Due to the widespread of these conditions, general dental practitioners and dental health care providers should be fully aware about the diagnosis, etiology and the appropriate management of these lesions and conditions.

\section{References with links to Crossref - DOI}

\section{References}

1. Bánóczy J, Rigó O, Albrecht M. Prevalence study of tongue lesions in a Hungarian population. Community Dent Oral Epidemiol. 1993;21:224-6.

2. Darwazeh AM, Pillai K. Prevalence of tongue lesions in 1013 Jordanian dental outpatients. Community Dent Oral Epidemiol. 1993;21:323-4.

3. Cebeci AR, Gülşahi A, Kamburoglu K, Orhan BK, Oztaş B. Prevalence and distribution of oral mucosal lesions in an adult Turkish population. Med Oral Patol Oral Cir Bucal. 2009;14:E272-7.

4. Motallebnejad M, Babaee N, Sakhdari S, Tavasoli M. An epidemiologic study of tongue lesions in 1901 Iranian dental outpatients. J Contemp Dent Pract. 2008;9:73-80.

5. Mathew AL, Pai KM, Sholapurkar AA, Vengal M. The prevalence of oral mucosal lesions in patients visiting a dental school in Southern India. Indian J Dent Res. 2008;19:99-103.

6. Reamy BV, Derby R, Bunt CW. Common tongue conditions in primary care. Am Fam Physician. 2010;81:627-34.

7. Kramer IR, Pindborg JJ, Bezroukov V, Infirri JS. Guide to epidemiology and diagnosis of oral mucosal diseases and conditions. World Health Organization. Community Dent Oral Epidemiol. $1980 ; 8: 1-26$

8. Vörös-Balog T, Dombi C, Vincze N, Bánóczy J. Epidemiologic survey of tongue lesions and analysis of the etiologic factors involved. Fogorv Sz. 1999;92:157-63.

9. Dos Santos PJ, Bessa CF, de Aguiar MC, do Carmo MA. Crosssectional study of oral mucosal conditions among a central Amazonian Indian community, Brazil. J Oral Pathol Med. 2004;33:7-12.

10. Al-Mobeeriek A, AlDosari AM. Prevalence of oral lesions among Saudi dental patients. Ann Saudi Med. 2009;29:365-8.

11. Kovac-Kovacic M, Skaleric U. The prevalence of oral mucosal lesions in a population in Ljubljana, Slovenia. J Oral Pathol Med. 2000;29:331-5.

12. Soto-Rojas AE, Villa AR, Sifuentes-Osornio J, Alarcón-Segovia D, Kraus A. Oral manifestations in patients with Sjögren's syndrome. J Rheumatol. 1998;25:906-10.

13. Campisi G, Margiotta V. Oral mucosal lesions and risk habits among men in an Italian study population. J Oral Pathol Med. 2001;30:22-8.

14. Mumcu G, Cimilli H, Sur H, Hayran O, Atalay T. Prevalence and distribution of oral lesions: a cross-sectional study in Turkey. Oral Dis. 2005;11:81-7.

15. Miloğlu O, Göregen M, Akgül HM, Acemoğlu H. The prevalence and risk factors associated with benign migratory glossitis lesions in 7619 Turkish dental outpatients. Oral Surg Oral Med Oral Pathol Oral Radiol Endod. 2009;107:e29-33.

16. Jainkittivong A, Aneksuk V, Langlais RP. Oral mucosal conditions in elderly dental patients. Oral Dis. 2002;8:218-23.

17. Vörös-Balog T, Vincze N, Bánóczy J. Prevalence of tongue lesions in Hungarian children. Oral Dis. 2003;9:84-7.

18. Costa SC, Hirota SK, Takahashi MD, Andrade H Jr, Migliari DA. Oral lesions in 166 patients with cutaneous psoriasis: a controlled study. Med Oral Patol Oral Cir Bucal. 2009;14:e371-5.

19. Shulman JD, Carpenter WM. Prevalence and risk factors associated with geographic tongue among US adults. Oral Dis. 2006;12:381-6.

\section{Acknowledgement}

The authors would like to thank Dr. Yousof S. Khader; Faculty of Medicine; Jordan University of Science \& Technology for his valuable help in biostatistics.

The study was supported by a grant from Deanship of Scientific Research, Jordan University of Science \& Technology (Grant number 115/2008). 